\title{
Assessment of developed tunics inspired from inlay work
}

\section{Himani Bhardwaj and Kanwaljit Brar}

Received: 03.02.2020; Revised: 19.03.2020; Accepted: 04.05.2020

See end of the paper for authors' affiliations Himani Bhardwaj

Department of Apparel and Textile Science, College of Community Science, Punjab Agriculture University, Ludhiana (Punjab) India

Email : himanibhardwaj93@ gmail.com
ABSTRACT : The investigation was carried out to design a line of tunics inspired from inlay work. Acceptance of respondents for prepared tunics was studied. Based on the preferential choices of the girls, six tunics were prepared using inlay motifs were rendered through machine embroidery. Evaluation of designed tunics was done by a sub-sample of thirty respondents. The most preferred tunic on the basis of silhouette was $\mathrm{D}_{5}$ (Mean score 4.6) which obtained first rank. Tunic $\mathrm{D}_{8}$ (mean score 5.2) was most preferred for the embellishments used. Both $\mathrm{D}_{5}$ and $\mathrm{D}_{8}$ tunics were most preferred for overall appeal. Quoted selling price of prepared tunic $\mathrm{D}_{5}$ was observed as adequate by most of the respondents $(76.67 \%)$. Probable profit margin possible on selling tunics were estimated from minimum 20.40 per cent to maximum 26.67 per cent. Mass production of tunics can reduce the cost of production.

KEY WORDS: Tunic, Inlay work, Motifs, Preferences, College-going girls

- HOW TO CITE THIS PAPER : Bhardwaj, Himani and Brar, Kanwaljit (2020). Assessment of developed tunics inspired from inlay work. Asian J. Home Sci., 15 (1) : 92-96, DOI: 10.15740/HAS/AJHS/15.1/9296. Copyright@ 2020: Hind Agri-Horticultural Society. 